\title{
Da Melancolia à Escrita: Um Estudo Psicanalítico sobre as Possibilidades da Sublimação
}

\author{
Débora dos Santos Silva ${ }^{I}$
}

\begin{abstract}
Resumo: A pesquisa pretendeu investigar a relação existente entre a melancolia: enquanto tipo clínico das neuroses narcísicas, e a escrita, buscando analisar as possibilidades desta associação para a diminuição das crises melancólicas, manifestas, principalmente, no sentimento de autodepreciação e fenômenos de autodestruição. Para tanto, foi empregada a abordagem qualitativa de pesquisa bibliográfica. Foram trabalhados os conceitos freudianos em torno do conflito entre Supereu e Eu, narcisismo, sublimação e idealização. Lacanianos, com foco na problemática do estádio do espelho e a constituição do Eu. Lambottianos, que versam sobre a ideia dos objetos estéticos enquanto mediadores transferenciais entre analisando e analista e promovedores da reinserção do sujeito à realidade. Além destes, foram trazidos ao debate teóricos como: Carvalho, Hassoun e Barros que tratam, mais especificamente, das questões envolvendo as limitações e possibilidades da sublimação, encarnada em escrita, para o abrandamento do sofrimento. E, teóricos da literatura que também abordam esta temática. Portanto, chegou-se ao entendimento de que é possível haver um apaziguamento do conflito entre Supereu e Eu, e, por conseguinte, uma melhora na afetividade do sujeito melancólico através da utilização do recurso da escrita, desde que esta utilização esteja pautada nos moldes da sublimação e não da idealização, e, a partir do momento em que esteja situada na relação psicanalítica.
\end{abstract}

Palavras-chave: Melancolia. Neurose Narcísica. Sublimação. Idealização. Escrita.

\section{Melancholy to Writing: \\ A Psychoanalytic Study of the Possibilities of Sublimation}

\begin{abstract}
This research aimed to investigate the relationship between melancholia: while clinical type of narcissistic neuroses, and writing, trying to analyze the possibilities of this association for the reduction of the melancholy crisis, manifested mainly in the sense of self-loathing and self-destruction phenomena. For that, we used a qualitative approach to bibliographic research. Freudian concepts were worked around the conflict between Superego and I, narcissism, sublimation and idealization. Lacanian, focusing on the mirror stage of the problem and the constitution of the self. Lambottianos, that deal with the idea of aesthetic objects as mediators transferential between analyst and patient and promoters of reintegration of the subject to reality. Besides these, were brought theoreticians to the debate such as Carvalho, Hassoun and Barros dealing more specifically the issues involving the limitations and possibilities of sublimation, embodied in writing, for relaxation of suffering. And theoretical literature that also address this issue. So come to the understanding that there can be a calming the conflict between superego and I, and therefore an improvement in the melancholic subject affection through the use of written rules, provided that the use is guided along the lines of sublimation and not of idealization, and, from the moment in which is situated in the psychoanalytic relationship.
\end{abstract}

Keywords: Melancholy. Narcissistic Neurosis. Sublimation. Idealization. Writing.

\footnotetext{
${ }^{1}$ Graduada em Psicologia pela Faculdade Leão Sampaio - FALS. Psicóloga (CRP 11/07381) de abordagem psicanalítica. Especialista em Educação Inclusiva com Ênfase em Atendimento Educacional Especializado e pós-graduanda (lato sensu) em Prática Docente do Ensino Superior pelas Faculdades Integradas de Patos - FIP. É membro titular do Comitê de Ética em Pesquisa da Faculdade de Juazeiro do Norte. E-mail para contato: deborassilva25@gmail.com ou debora.psicanalise@hotmail.com
} 


\section{Introdução}

A melancolia, entendida enquanto tipo clínico das neuroses narcísicas manifestar-se-ia, quando em períodos de crise, através de um desprezo ou sentimento de desvalia que o sujeito passa a dirigir contra si. Na gênese desta afecção existiria um intenso conflito entre Supereu e Eu. Conflito este que, a depender de como o sujeito possa lidar com ele, pode levá-lo a recorrer ao suicídio enquanto tentativa de saída do sofrimento ou do nada a que se vê identificado.

Ao longo da história, a melancolia esteve associada à genialidade e à arte, sendo que muitos sujeitos acometidos por este pathos recorriam, deliberadamente ou não, à escrita no tentame de extravasar ou de deixar vazar a excessiva produção de pensamento/tormento, seja por meio da ficção ou da confissão. Fernando Pessoa e Clarice Lispector são exemplos de escritores que utilizaram a escrita com alguns toques de autobiografia. No entanto, em certos casos a atividade criativa não logrou êxito e o sujeito terminou por ceder aos imperativos do Supereu. No rol de escritores suicidas podemos citar os portugueses: Florbela Espanca e Mario de Sá-Carneiro, a britânica: Virgínia Woolf e a norte-americana: Sylvia Plath. Embora não podendo dizer sobre a posição subjetiva em que eles transitavam, percebe-se em seus escritos uma espécie de manifestação melancólica do eu-lírico.

É evidente que nestes autores a escrita não possibilitou um abrandamento do conflito por qual passavam frente a eles mesmos e ao contexto histórico em que viviam. No entanto, estaria o suicídio deles associado a uma sublimação perpassada por um aumento dos ideais do eu? Onde esbarra a sublimação? Quais as possibilidades da atividade criativa, especificamente da escrita, para trazer alívio ao sofrimento? Seria possível assegurar ao sofrimento melancólico, na clínica psicanalítica, uma escritura sublime sem o risco da passagem ao ato pelas vias do suicídio?

Portanto, a pesquisa pretendeu investigar a aparente relação entre melancolia e escrita, fazendo uma incursão, para isso, em conceitos referentes à literatura ficcional ou confessional. Neste sentido, buscou-se fazer um levantamento da bibliografia psicanalítica em torno da melancolia e sua relação com a escrita enquanto recurso de saída do sofrimento, no intuito de entender se a sublimação (enquanto um dos destinos da pulsão) coloca-se como modalidade ou determinante na maneira melancólica de perceber e de se posicionar frente ao mundo e o porquê e onde tal mecanismo esbarra em sua tentativa de resolução.

\section{Método}

Para realizar a investigação, recorremos à abordagem qualitativa de cunho bibliográfico. Pois que a pesquisa bibliográfica possibilita o recolhimento de dados dispersos na história, já que, para se 
conhecer e entender os fatos outrora ocorridos embasar-se em dados já descritos é a melhor maneira de consegui-lo (GIL, 1999).

A investigação pretendeu ser em psicanálise, diferente, segundo Figueiredo e Minerbo (2006) de uma pesquisa com o método psicanalítico, já que a pesquisadora é psicóloga e uma pesquisa com o método psicanalítico só poderia ser realizado por um psicanalista. Portanto,

Chamemos de 'pesquisa em psicanálise', no sentido amplo, um conjunto de atividades voltadas para a produção de conhecimento que podem manter com a psicanálise propriamente dita relações muito diferentes. Em certas circunstâncias, por exemplo, observa-se uma respeitosa distância: ora as teorias da psicanálise tornam-se 'objeto' de estudos sistemáticos, ora de estudos históricos, ora de reflexões epistemológicas; outras vezes, alguns conceitos psicanalíticos são mobilizados como instrumentos para a investigação e compreensão de variados fenômenos sociais e subjetivos [...] (FIGUEIREDO; MINERBO, 2006, p. 258).

Uma vez esclarecido o modo de pesquisa, vale dizer que utilizamos, como unidade de análise, os textos freudianos: que tratam dos conceitos em torno do conflito entre Supereu e Eu, narcisismo, sublimação, idealização e disjunção pulsional. Lacanianos: que trabalham categorias como: gozo, estádio do espelho, tentativas de saída da dor melancólica. Lambottianos: que enfatizam a concepção da melancolia enquanto neurose narcísica e tratam da ideia da constituição de objetos estéticos dentro da relação transferencial: psicanalista/psicanalisando, como maneira de possibilitar a fabricação de uma identidade, de uma imagem de si.

Foram trabalhados também os textos de Carvalho que versam sobre a relação entre psicanálise, literatura e suicídio. Assim como foi feito um levantamento bibliográfico em livros e dissertações em torno de outros teóricos da psicanálise e da literatura que tratam da relação entre melancolia e escrita.

\section{As origens do conceito de Melancolia}

A palavra melancolia deriva do grego melas e kholé, que significa, respectivamente, negro e bile (ROUDINESCO; PLON, 1998) e denuncia, assim, o aspecto negativista que caracteriza tal estado de humor, foi experimentando ao longo da história da humanidade vários sentidos no que se refere a seu estatuto. Antes da modernidade a perspectiva acerca da melancolia voltava-se para as questões envolvendo, de um lado, os quatro humores (fleuma, sangue, bile amarela e bile negra) especificamente o desequilíbrio na bile negra, e de outro, a ideia de que a melancolia estaria associada à genialidade e a um estado ou tendência à tristeza que era, também, motor ao ato criativo. Porém, com o advento da modernidade, sobretudo com a interferência direta da medicina, a melancolia passa 
a ser enquadrada e tratada como uma doença com sinais e sintomas bem delimitados (PERES, 2010), passando a ser associada à depressão ou ao transtorno bipolar.

A psicanálise aproximou a melancolia, a partir dos estudos iniciais de Freud (1996[18921899]), às neuroses atuais, e como tal, estaria relacionada a distúrbios na esfera contingente da sexualidade. Sendo um estado afetivo passível de ser alterado com as modificações prescritas pelo terapeuta. Mais tarde, Freud irá trabalhá-la com base no comparativo do afeto do luto e destacará a questão central das crises melancólicas, qual seja: o sentimento de autodesvalia e autodestruição (FREUD, 2007[1917]).

A partir daí, seus estudos o levam a inseri-la na categoria de neurose narcísica, diferente das neuroses de transferência - onde o conflito desenvolve-se em torno do Eu e do Id, das psicoses - onde o conflito diz respeito ao Eu e o mundo externo (FREUD, 2007[1924]) e das neuroses atuais, pois o conflito psíquico na melancolia se situaria entre o Supereu e o Eu.

Na melancolia, o Supereu que exerce as funções de observação, consciência, e veículo do ideal do eu, se revelaria um perverso carrasco, insultando e maltratando o Eu que se tornou fraco frente a ele (FREUD, 1996[1933]).

\section{Melancolia: Neurose Narcísica ou Psicose?}

Diversos psicanalistas pós-freudianos, baseados no ensino de Lacan, acreditam que a melancolia é um tipo clínico da estrutura psicótica. Quinet (2009), a exemplo, diz ser ela a manifestação da dor de existir, do fardo de viver, da desistência e renúncia ao desejo e concessão por inércia aos imperativos do Supereu, onde não há um significante que barre o gozo mortificante.

A melancolia revelaria, assim, uma falta de referência ao Nome-do-Pai, que traduziria a metáfora paterna ao promover a deposição do lugar alienante em que a criança originalmente se encontra de ser o falo da mãe, para que possa existir separada desta, estabelecendo-se enquanto sujeito desejante (COSTA, 2010).

Contudo, segundo Lambotte (2001), o próprio Lacan disse que o melancólico está no simbólico. É assim que ao se identificar com o vazio e se comparar ao nada, este nada se transforma num significante mestre, gerando a manutenção de um discurso que se endereça a outrem.

Lambotte resgata a concepção freudiana da melancolia enquanto neurose narcísica. Nesta afecção haveria uma falha na constituição do narcisismo, no registro do imaginário, lá, onde o estádio do espelho, a partir dos seis meses de idade, deveria oferecer ao bebê a percepção de sua individualidade e identidade à medida que confirmado pelo olhar do Outro. 


\section{A gênese da Melancolia}

O melancólico, em contrapartida, teria recebido quando de seu olhar no espelho o olhar indiferente do Outro, terminando por se identificar com este olhar enfraquecedor para a constituição da imagem e assumindo uma repugnância para com o próprio Eu (BRASIL, 2001). Porém, tentaria desenhar tal imagem de si no intuito de sair da tristeza e do nada em que se vê identificado, utilizando recursos como: “[...] autocrítica e refúgio na intelectualidade [...] prazer da expulsão e do rechaço de qualquer investimento [...] desdém pelo mundo [...]" (BRASIL, 2001, p. 12).

Sobre isso, pode-se apontar que o adoecimento melancólico suscita um pensar em demasia. Sendo, segundo Lambotte (2000, p. 10) a "[...] doença que mais leva a pensar [...] que alimenta tanto a reflexão filosófica quanto a verve poética [...]".

Esta hemorragia psíquica somada à inscrição falha no registro do imaginário e à disjunção entre pulsões de vida e pulsão de morte conduziria o sujeito à negatividade, à falta de vontade em investir na realidade e até ao suicídio. No entanto, Mees (2001, p. 17), indica que "[...] Como potencial artista das palavras, o melancólico pode vir a produzir, a partir do vazio, algo que se dirija a um outro, um público, a leitores [...]”. Comungando de similar ideia, Bartucci (2001, p. 11) defende a arte enquanto "[...] possibilidade de [...] estruturar [...] a realidade de modo pessoal e estilizado, constituindo destinos possíveis para as forças pulsionais [...]”. O próprio Rubem Alves (2008), em Ostra feliz não faz pérolas, recorre a uma metáfora marinha para demonstrar as problemáticas de que se serve um artista durante $o$ ato criativo.

Nesse sentido, a arte em geral e a literária, particularmente a escrita confessional, exemplo: cartas, diário ou mesmo elementos ficcionais combinados com traços autobiográficos, podem servir como tentativa de saída ou diminuição do negativismo e sensação de inutilidade, na medida em que promova a organização e o direcionamento dos pensamentos incessantes e permita ser instrumento de mediação entre sujeito e objeto. Com efeito, segundo Gusdorf, citado por Delprete (2010, p. 09), “[...] o homem que conta a sua vida compreende, na medida em que se recria através da escrita, a singularidade das experiências humanas e sabe, por isso, que a vida de cada um merece ser narrada $[\ldots] "$.

Nesse prisma, a escrita literária é entendida aqui enquanto possuindo um fim em sua própria criação, não sendo passível a atribuição de um único sentido, ou seja, “[...] Ela é, através do próprio ato de escrever, pesquisa e invenção constante dos caminhos da linguagem, da existência e, consequentemente, da liberdade.” (ALMEIDA; PEIXOTO JÚNIOR, 2010, p. 141). 


\section{A sublimação na Melancolia}

Freud, em nenhum momento em que tratou da questão da melancolia o fez associando-a diretamente à sublimação. Este tipo de reflexão vem sendo realizada pelos pós-freudianos.

Para Lambotte (2001) o objeto estético enquanto mediador transferencial, artifício de contemplação e indicador de gozo pode provocar a reinserção do sujeito à realidade. A sublimação, na medida em que não é um engrandecimento do objeto através da idealização, mas um processo que envolve a satisfação da pulsão através de outras metas tornar-se-ia uma alternativa, já que não aumentaria o grau das exigências do Eu (FREUD, 2004[1914]), permitindo, talvez, uma redução do sadismo do Supereu.

Não obstante, outros estudiosos têm apontado os limites da escrita em conter o sofrimento melancólico, embasados nos casos de literatos suicidas famosos (como os citados na introdução) e de sujeitos em análise. Exemplos destes estudiosos: Carvalho (2001; 2006; 2010), Hassoun (2002), e Barros (2010).

Carvalho (2001) defende a ideia de que a escrita pode fazer papel tanto de contenção quanto de excesso. Contenção das angústias e de um real que necessita ser elaborado. Excesso de dor, repetição e mobilização das pulsões destrutivas. Além disso, a autora diz que: “[...] Se o júbilo, o lúdico e o prazeroso fazem parte do escrever, contudo não estão ausentes dele o perigo e a angústia. Remédio para uns, veneno para outros" (CARVALHO, 2006, p. 21). Estas ideias são desenvolvidas pela autora para mostrar as limitações da sublimação que, segundo ela, veio sendo concebida desde Freud de três modos, a saber: a partir de uma perspectiva freudiana inicial que credita à mesma (à sublimação) a capacidade de promover um abrandamento do conflito psíquico que gera sofrimento. A segunda está relacionada à perspectiva lacaniana, neste sentido, a sublimação promoveria uma espécie de inscrição subjetiva ao favorecer ao intenso sofrimento uma saída pela via da criação. A terceira concepção diz ser a sublimação algo que leva o sujeito a fazer laço social, a transformar algo que é particular em algo social ou geral (CARVALHO, 2010). Carvalho, não obstante, chama constantemente a atenção para o lado disfuncional da sublimação.

Hassoun (2002), por sua vez, ao referir-se aos autores que parecem marcar seus trabalhos artísticos da melancolia como tentativa de criar um objeto próprio que possa contornar o luto infindável que sentem, diz que a atividade da escrita, embora pautada numa melancolia sublimada, antes de trazer conforto, termina por nutrir "[...] o enigma de uma insondável crueldade [...]" (HASSOUN, 2002, p. 152).

Barros (2010, p. 126) dirá que mesmo sendo uma atividade sublimatória, "A escrita nem sempre é remédio, pois não barra integralmente as pulsões destrutivas, [...] pode se fazer poesia até a morte, pulsando a força da letra. A escrita ordena o pensamento, barra o gozo, mas não cura [...]". 
Existem divergências no que diz respeito às possibilidades da escrita enquanto recurso de saída do sofrimento melancólico. Estes impasses, entretanto, reclamam uma maior investigação, sobretudo se pensarmos no exercício da escrita confessional, perpassada pela fala, dentro do setting terapêutico, na clínica psicanalítica.

Ou seja, parte-se da hipótese que a escrita pode conter o sofrimento melancólico à medida que, no ato de escrever esteja presente não só o sujeito que sofre, mas o profissional que acolhe o sofrimento e os pares - aos quais possa remeter tal escrita, encontrando espaços sublimes, através da contemplação, porém, não mediada pela idealização do objeto estético. Assim,

[...] a pessoa que expõe sua vida ao público está também em busca do autoconhecimento. $\mathrm{O}$ processo de autoconhecer-se acontece na medida em que o autobiógrafo vai se repensando através da escrita, e, em conseqüência, recriando o seu Eu (GUSDORF apud DELPRETE, 2010, p 09).

Neste caso, o exercício da escrita poderia talvez oferecer aos melancólicos em descompensação uma melhoria de sua condição, sua melhor inserção social e, principalmente, um distanciamento da vontade de autoaniquilação que não raro perpassa seus pensamentos e volição.

\section{Considerações Finais}

Muito se falou sobre as possibilidades e as limitações da escrita para o abrandamento do sofrimento melancólico. A sublimação, durante o desenvolvimento da leitura, parece ser um mecanismo a que o Melancólico enquanto potencial artista das palavras utiliza, de maneira deliberada ou não, para contornar a tristeza que padece.

Trabalhou-se na realização deste texto com a hipótese de que a escrita pode trazer alívio ao sofrimento melancólico desde que esteja perpassada pela fala, no setting psicanalítico, e na medida em que possa ser objeto de contemplação tanto para o sujeito que escreve quanto para os pares aos quais possa remeter ou direcionar tal escrita. Escrita esta que pode ser tanto de caráter ficcional quanto confessional.

Com isto, não quer se dizer que todo escritor é melancólico, porém, talvez, todo melancólico possa ser um escritor. A questão é que a sublimação, per se, não traz alívio. O que desperta atenção, sobretudo, se procurarmos conhecer a biografia de escritores que se tornaram suicidas, é o fato de que o sujeito idealiza não só a própria escrita como também a forma como o público irá interpretá-la. Talvez esta seja a problemática central. A sublimação cumpre seu papel, porém, o conflito entre Supereu e Eu, precisamente a força do Supereu ante o Eu no padecimento melancólico faria com que 
os ideais se exacerbassem e aumentassem, produzindo assim a queda do Eu. A Psicanálise aqui, enquanto terapêutica, poderia exercer um papel importante para uma saída do sofrimento paralisante.

Estas são apenas indagações que carecem ainda de comprovação, porém, podem servir para levar a novas pesquisas e inquirições, e, assim, promover ajuda para a tristeza, inércia e tendência a autoaniquilação que está presente nos melancólicos.

\section{Referências}

ALMEIDA, L. P.; PEIXOTO JÚNIOR, C. A. Escrita literária: linguagem, existência e ruptura com a tradição. In. Alceu, 2010. Disponível em: < http://revistaalceu.com.puc-rio.br/media/Alceu21_9.pdf $>$. Acesso em: 05 out. 2013.

ALVES, Rubem. Ostra feliz não faz pérola. Editora Planeta do Brasil: São Paulo, 2008.

BARTUCCI, G. Apresentação. In. BARTUCCI, G. (Org.) Psicanálise, literatura e estéticas de subjetivação. Rio de Janeiro: imago editora, 2001.

BRASIL, M. A. Fora de si, Fora do mundo. In. Os nomes da tristeza. Revista da associação psicanalítica de Porto Alegre, Ano IX, n. 21. Porto Alegre: APPOA, 2001.

BARROS, E. L. S. Os enigmas do dizer poético de Florbela Espanca. In. Psicanálise \& Barroco em revista, v.8, n.1, 2010 .

CARVALHO, A. C. Pulsão e simbolização: limites da escrita. In. BARTUCCI, G. (Org.). Psicanálise, literatura e estéticas de subjetivação. Rio de Janeiro: Imago, 2001.

. Limites da sublimação na criação literária. In. Estudos de Psicanálise. Rio de Janeiro, n. 29, setembro 2006.

. A toxidez da escrita como destino da sublimação em David Foster Wallace. In. Psicologia USP. São Paulo, 2010.

COSTA, T. A contribuição de Jacques Lacan. In. Psicanálise com crianças. 3 ed. Rio de Janeiro: Zahar, 2010 (Coleção passo-a-passo).

DELPRETE, C. C. Só podemos expor o que somos. In. As recordações de infância na crônica de Rubem Braga e no conto de Graciliano Ramos. Porto Alegre, 2010 (monografia de graduação).

FIGUEIREDO, L. C. MINERBO, M. Pesquisa em Psicanálise: algumas idéias e um exemplo. In. Jornal de Psicanálise. São Paulo, 39 (70), 2006.

FREUD, S. Extratos dos documentos dirigidos a Fliess (1950[1892-1899]). In. Publicações prépsicanalíticas e esboços inéditos (1886-1899). Obras psicológicas completas de Sigmund Freud: edição standard brasileira. Rio de Janeiro: Imago, 1996.

À Guisa de introdução ao narcisismo (1914). In. Escritos sobre a psicologia do inconsciente. Volume I (1911-1915). Rio de Janeiro: imago, 2004. 
Luto e melancolia (1917). In. Escritos sobre a psicologia do inconsciente. Volume II (19151920). Rio de Janeiro: Imago, 2007.

Neurose e Psicose (1924). In. Escritos sobre a psicologia do inconsciente. Volume III (1923-1938). Rio de Janeiro: Imago, 2007.

. A dissecção da personalidade psíquica (1933). In. Novas conferências introdutórias sobre psicanálise e outros trabalhos (1932-1936). Edição standard (...). Rio de Janeiro: Imago,1996.

GIL, A. C. Métodos e técnicas de pesquisa social. São Paulo: Atlas, 1999.

HASSOUN, J. A crueldade melancólica. Rio de Janeiro: Civilização brasileira, 2002.

LAMBOTTE, M-C. Estética da melancolia. Rio de Janeiro: companhia de Freud, 2000.

A deserção do outro. In. A clínica da melancolia e as depressões. Revista APPOA. Revista da associação psicanalítica de Porto Alegre, nº 20, junho, 2001.

MESS, L. A. As várias cenas da melancolia e da depressão. In. A clínica da melancolia e as depressões. Revista APPOA. Revista da associação psicanalítica de Porto Alegre, nº 20, junho, 2001.

PERES, U. T. Depressão e Melancolia. $3^{\text {a }}$ ed. Rio de Janeiro: Jorge Zahar Ed, 2010.

QUINET, A. Psicose e laço social: esquizofrenia, paranóia e melancolia. 2a ed. Rio de Janeiro: Jorge Zahar Ed., 2009.

ROUDINESCO, E. PLON, M. Dicionário de Psicanálise. Rio de Janeiro: Zahar, 1998.

Como citar este artigo (Formato ABNT):

SILVA, D.S. Da Melancolia à Escrita: Um estudo psicanalítico sobre as possibilidades da Sublimação. Id on Line Revista de Psicologia de 2015, vol.9, n.26, Supl. Esp. p. 181-189. ISSN 1981-1189.

Recebido: 17/01/2015

Aceito: 12/02/2015 